Research Article

\title{
Study on the Microscopic Mechanism of Spontaneous Combustion and Oxidation Kinetics of Water-Leached Coal
}

\author{
Naifu Cao $\mathbb{D}^{1,2,3}$ Gang Wang, ${ }^{2,3}$ and Yuntao Liang ${ }^{2,3}$ \\ ${ }^{1}$ China Coal Research Institute, Beijing 100013, China \\ ${ }^{2}$ State Key Laboratory of Coal Mine Safety Technology, Fushun 113122, China
}

${ }^{3}$ CCTEG Shenyang Research Institute, Fushun 113122, China

Correspondence should be addressed to Naifu Cao; caonaifu@syccri.com

Received 2 April 2021; Accepted 2 November 2021; Published 23 November 2021

Academic Editor: Shahid Hussain

Copyright (C) 2021 Naifu Cao et al. This is an open access article distributed under the Creative Commons Attribution License, which permits unrestricted use, distribution, and reproduction in any medium, provided the original work is properly cited.

In this article, a series of experiments have been carried out to study the spontaneous combustion and oxidation mechanism of coal after water immersion and investigate its tendency to spontaneous combustion, analyze the difficulty of spontaneous combustion of coal samples under different water immersion conditions, and establish a kinetic model of water immersion coal oxidation (taking the Bulianta 12\# coal as a case study). They rely on physical oxidation adsorption, scanning electron microscopy (SEM), Fourier-transform infrared spectroscopy (FTIR), thermogravimetry, and oil bath heating. SEM has been used to analyze the characteristics of coal pore structure under different water immersion conditions (water-saturated coal samples under different water loss conditions until the coal samples are completely dried); FTIR served to investigate the characteristics of the molecular chemical structure of the coal surface before and after the coal is immersed in water. Through programmed temperature oxidation experiments combined with FTIR analyses and gas chromatographic (GC) analysis of gaseous products, it has been possible to study the changes of molecular structure and gas products on the surface of coal samples at different temperatures and water immersion conditions. The oxidation reaction rate of the 12\# coal samples of Shendong Mine's Bulianta Mine under different water content conditions during the spontaneous combustion process has been quantitatively studied. The difficulty of spontaneous combustion of coal samples has been correspondingly addressed. A kinetic model from the perspective of oxygen consumption has been proposed. Thermogravimetry-differential scanning calorimetry (TG-DSC) has been used to analyze and study the exothermal oxidation process before and after coal immersion. From the perspective of the exothermic intensity of the coal-oxygen reaction, an oxidation kinetic model for immersed coal samples has been developed to qualitatively determine its spontaneous combustion tendency. Results have shown that the increase in the specific surface area increases the risk of spontaneous combustion, and coal samples after soaking and drying have a stronger tendency to spontaneous combustion than raw coal. The moisture content of the coal sample leading to the easiest ignition conditions is $16.05 \%$. Regardless of the moisture content, the critical temperature is maintained at $65-75^{\circ} \mathrm{C}$, and the temperature of the left coal in the goaf should be prevented from exceeding this critical value.

\section{Introduction}

The geological structure of the shallow coal seam in the Shendong mining area usually results in a large amount of water in the upper coal seam goaf. When coal is mined at a distance of about 20-60 m, the upper coal goaf needs to be drained in advance. In the process of water drainage, water and gas displacement occur. After air enters the overlying goaf, it is very easy that this causes the coal leftover in the overlying goaf to oxidize and spontaneously burn [1]. After being affected by the mining of the lower coal, the surface can collapse, the remaining coal and coal pillars in the upper layer can be broken, and the upper and lower coal mined areas may enter in contact to further increase the spontaneous combustion risk of the upper coal [2]. Field observations have shown that when the lower coal seam is mined, the spontaneous combustion high-temperature area in the upper goaf usually appears near the coal seam flooding line, 
indicating that the spontaneous combustion of the coal seam can be more relevant after flooding. Regarding the influence of water on the spontaneous combustion of coal, several studies have been published. For instance, $\mathrm{Xu}$ et al. analyzed in detail the heat of wetting, dissolution, swelling, hydrolysis, vaporization, and condensation of coal [3]. Jones and Townend proposed that moisture plays a catalytic role in the formation of peroxygen complexes, thereby promoting spontaneous combustion [4]. Krger and Beier published similar results [5]. Zheng et al. studied the effect of high moisture content on coal spontaneous combustion, highlighting that, in the low-temperature stage, high moisture content promotes the formation of peroxygen complexes and promotes coal-oxygen recombination [6]. At $80-110^{\circ} \mathrm{C}$, the latent heat of evaporation and vaporization in the presence of high moisture content has an inhibitory effect on the coal-oxygen reaction. Banerjee analyzed the oxidation kinetics of coal on the basis of experimental results obtained in the differential thermal analyzer, underlining that, in the low-temperature stage of coal, due to moisture evaporation, heat is difficult to accumulate, and the coal temperature rises very slowly [7]. Relevant technicians at the University of Nottingham in the United Kingdom have highlighted that the evaporation and heat absorption of water in the coal hinder the rise of coal temperature [8]. He and Wang found that the influence of moisture on the spontaneous combustion of coal can be determined by two aspects: heat release and oxygen absorption [9]. Studying the mechanism of spontaneous combustion in water-immersed coal seams is therefore helpful to distinguish the spontaneous combustion high-temperature range of coal seams in the water-immersed goaf of the Shendong mining area, aiming at spontaneous combustion prevention [10].

Based on the analysis and summary of previous research results, it can be seen that, currently, there are not many studies dealing with the influence of moisture on the spontaneous combustion of coal, and it is still hard to explain the phenomenon that the number of spontaneous fires greatly increases after coal is flooded. Actually, while coal-oxygen compound theory is widely adopted in explaining the theory of coal spontaneous combustion, it cannot explain the spontaneous combustion of water-immersed coal. Therefore, the nature of the spontaneous combustion of water-immersed coal is still unclear. More in detail, regarding the influence of moisture on the oxidation characteristics of coal upon spontaneous combustion, most published works only focus on a single parameter at a time. Although some scholars have noticed an optimal humidity level that makes coal prone to low-temperature oxidation, most of the studies are only qualitative, and no specific indicators and methods are given. In the underground, due to the influence of mining, the coal body may lose water due to the blow of wind or increase its water content due to infiltration. However, when predicting coal spontaneous combustion, coal samples with natural moisture are often used for experiments, and the influence of moisture on coal spontaneous combustion gas products is not considered. This work aims to give a contribution in this direction by addressing the aspects that, as just commented, still deserve investigation.

\section{Specific Surface Area and Porosimetric Characterization}

Specific surface area and pore size distribution of coal samples have been investigated by an Autosorb-iQ-C automatic physical and chemical adsorption instrument. The coal samples collected on site were processed to a powder form of $0.075-0.109 \mathrm{~mm}$ (180-200 mesh) and then immersed in water and dried. About $2 \mathrm{~g}$ of the coal sample was put into a physical adsorption container: the total weight of the container and the coal sample was measured, and then liquid nitrogen was put into the cold trap. At the beginning of the experiment, the coal sample needs to be pretreated with desorption. From the beginning of the pretreatment, a vacuum was kept until the experimental apparatus was filled with nitrogen. At the beginning of the experiment, the temperature was increased at a rate of $5^{\circ} \mathrm{C} / \mathrm{min}$. After the temperature reached $100^{\circ} \mathrm{C}$, it was kept at this value for $100 \mathrm{~min}$, and then it was increased again at a rate of $5^{\circ} \mathrm{C} / \mathrm{min}$. After reaching $110^{\circ} \mathrm{C}$, it was kept at this value for $600 \mathrm{~min}$ and then left to naturally cool down to room temperature. After the pretreatment, the experiment started. Nitrogen was injected into the test tube containing the coal sample. At $-196^{\circ} \mathrm{C}$, the nitrogen adsorption capacity of the coal sample at different pressures was measured, and the adsorption curve was used to analyze the experimental results.

The BET theory has been used to calculate the specific surface area of the coal samples based on a multimolecular layer adsorption model [11]. Due to the complexity of the coal surface structure, the adsorption of oxygen, nitrogen, and other gases is better represented by multimolecular layer adsorption. The BET equation is

$$
\frac{P}{V\left(P_{0}-P\right)}=\frac{1}{V_{m} C}+\frac{C-1}{V_{m} C} \frac{P}{P_{0}}
$$

where $P$ is the partial pressure of $N_{2}, P_{0}$ is the saturated vapor pressure of $N_{2}$ at $-196^{\circ} \mathrm{C}, V$ is the actual amount of $N_{2}$ adsorbed on the surface of coal sample, $V_{m}$ is the single-layer $\mathrm{N}_{2}$ saturation adsorption capacity of the sample, and $C$ is a constant related to adsorption capacity. The fitting of data allows obtaining equation parameters and the specific surface area of the samples under investigation. Through the analysis of a large amount of experimental data, it was found that when $P / P_{0}$ is in the range of $0.05-0.35$, linear fitting (as reported in Figure 1) gave very satisfactory results (thus yielding accurate values for the specific surface area).

Through the test results, it was found that the specific surface area of different coal samples was obviously different and relatively large in general (as a reference value, for the Bulianta 12\# raw coal, this area is $8.342 \mathrm{~m}^{2} / \mathrm{g}$ ). A large specific surface area means that the chance of coal to enter in contact with $\mathrm{O}_{2}$ molecules is obviously good. This can improve the coal tendency to spontaneous combustion.

Since the multilayer adsorption phenomenon is essentially based on a condensation process, the density functional theory (DFT) method has been here used to study the pore size distribution of coal, in the range $0-180 \mathrm{~nm}$ with subdivision into micropores $(<2 \mathrm{~nm})$, mesopores $(2-50 \mathrm{~nm})$, 


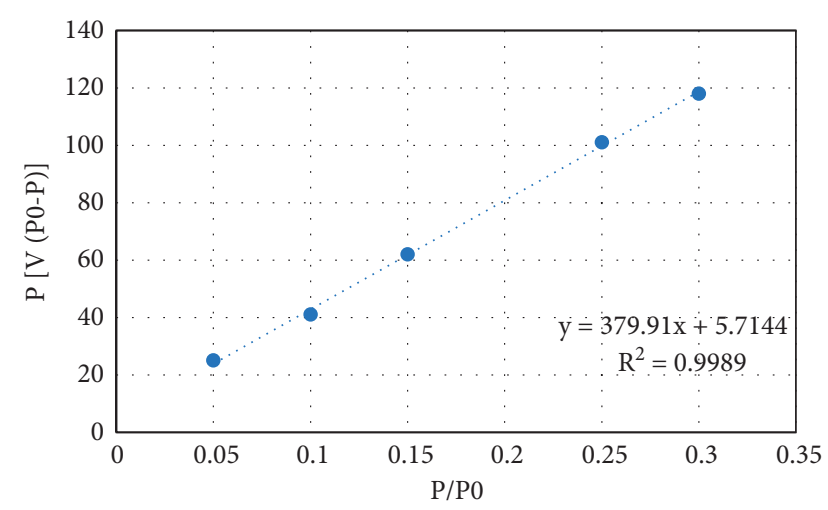

FIgURE 1: Multipoint BET method for measuring the specific surface area. Fitting experimental data with equation (1) was performed by plotting the left-hand side of equation (1) versus $P / P_{0}$ to obtain $C$ and $V_{m}$ BET parameters.

and macropores (>50 nm) [12]. Results for the Bulianta 12\# raw coal sample are reported in Figure 2, where $\mathrm{d} v(r)$ represents the differential of the total pore volume as a function of the pore radius. In general, it was found that the micropores account for $10-20 \%$ of the total porosity, the mesopores for $50-60 \%$, and the macropores for $20-30 \%$. Since the diffusion of gas molecules in the mesopore region is mainly of Knudsen and transitional type, the relevance of mesopores is beneficial to the diffusion and permeation of $\mathrm{O}_{2}$ molecules, thus providing conditions for $\mathrm{O}_{2}$ adsorption and coal oxidation.

\section{SEM Analyses}

SEM analyses were carried out with a Hitachi E-1045 ion sputtering instrument and a S-4800 field emission scanning electron microscope. The raw coal sample and the waterimmersed and dried coal samples were put into the cell of the ion sputtering instrument, and the sputtering trajectory of the gold element is controlled by the magnetic field, so that the gold element coating on the surface of the experimental sample results as uniform as possible. After spraying for 2 to $4 \mathrm{~min}$, the nonconductive charging phenomenon was eliminated, and the observation effect was significantly improved. Then, the samples were uniformly bonded to conductive tape and put into the SEM chamber to observe and scan the microscopic morphology of the coal surface. At the same time, for different points and surface positions of the samples, an energy spectrometer was used for element qualitative and semiquantitative analysis. Figure 3 illustrates SEM micrographs for the reference coal sample before and after water immersion. It can be observed that the pore structure of the sample before and after water immersion is significantly different (more porous is the sample after water immersion). The specific surface areas of the two samples are also different, which is related to the development of pores and cracks that cause differences in the amount of adsorbed oxygen and affect the early oxidation process of coal (spontaneous combustion). Therefore, from the perspective of the effect of porous microstructure on $\mathrm{O}_{2}$ adsorption, the

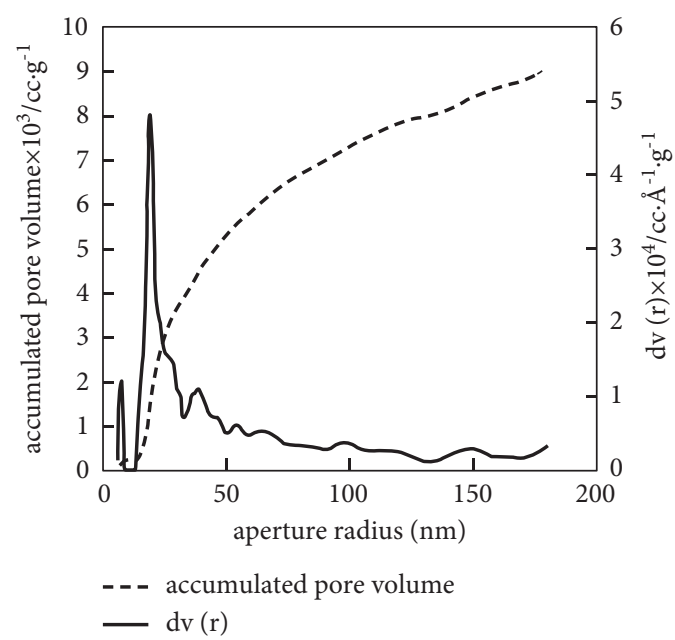

Figure 2: Cumulative (left $y$-axis) and differential (right $y$-axis) pore size distribution for Bulianta 12\# raw coal sample.
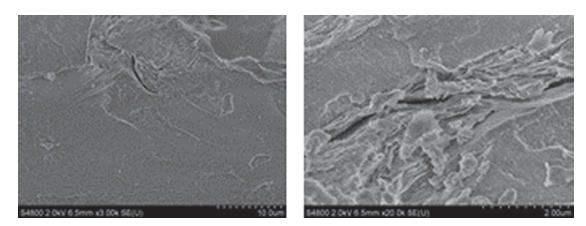

FIgURE 3: SEM images of the Bulianta 12\# raw coal sample before (a) and after (b) water immersion.

coal samples show a high tendency to spontaneous combustion.

\section{Determination of Surface Active Functional Groups}

The macroscopic appearance of coal is a complex mixture composed of aromatic microcrystalline structure and fatty structure with multiple pore structures and the presence of minerals. The main part of the coal molecular structure is aromatic, with poor condensation degree, and it also includes main functional groups such as oxygen-containing functional groups and aliphatic hydrocarbon structure.

In this context, the IR spectrum is of relevance as it reflects the characteristics of the molecular structure. The mid-infrared zone (wavenumber $4000-400 \mathrm{~cm}^{-1}$ ) of the IR spectrum is the vibration zone of common chemical groups. According to the vibration form of different groups, it mainly includes $\mathrm{X}-\mathrm{H}$ stretching vibration zone (4000-2500 $\left.\mathrm{cm}^{-1}\right)$, triple bond and cumulative double bond zone (2500-1900 $\left.\mathrm{cm}^{-1}\right)$, double bond stretching vibration zone $\left(1900-1200 \mathrm{~cm}^{-1}\right), X-Y$ stretching vibration, and $\mathrm{X}-\mathrm{H}$ deformation vibration zone $\left(<1650 \mathrm{~cm}^{-1}\right)$. As the content of different functional groups in the coal molecular structure is different, the vibration intensity will also be different, so the relative content of the functional groups in the coal molecular structure can be semiquantitatively analyzed according to the intensity of the absorption peaks of different functional groups and the vibration position of the 
molecular groups. The main characteristic peaks and their assignment in the IR spectrum for coal structure are listed in Table 1.

The experimental tests have been carried out with a Bruker VENTEX80 in situ diffuse reflectance FTIR spectrometer. In order to obtain the infrared spectrum of coal in its original state, the distribution of main functional groups in the molecular structure of coal at room temperature was tested in air atmosphere. The number of scans was set to 32 , the resolution to $4 \mathrm{~cm}^{-1}$, and the spectrum scan range was $4000-400 \mathrm{~cm}^{-1}$. The particle size range of the coal sample was $0.075-0.109 \mathrm{~mm}$. In order to reduce the interference of the scattering peak, the coal sample was mixed with $\mathrm{KBr}$ powder in a ratio of $1: 1$. Figure 4 illustrates the IR spectra for three coal samples belonging to the same mining area. The molecular structure of coal contains aromatic hydrocarbons, aliphatic hydrocarbons, and oxygen-containing functional groups [14]. These three types of structures appear as multiple peaks in the IR spectrum, including aromatic hydrocarbon $\mathrm{CH}$ structure at $3050-3030 \mathrm{~cm}^{-1}$ wavenumber, aromatic hydrocarbon $\mathrm{C}=\mathrm{C}$ skeleton at $1604-1599 \mathrm{~cm}^{-1}$ wavenumber, methyl and methylene groups at $2875-2858 \mathrm{~cm}^{-1}$, hydroxyl at $3700-3200 \mathrm{~cm}^{-1}$, carbonyl at $1790-1770 \mathrm{~cm}^{-1}$, carboxyl at $1715-1690 \mathrm{~cm}^{-1}$, and ether bond at $1330-1060 \mathrm{~cm}^{-1}$.

4.1. Aromatic Hydrocarbons. The structure of aromatic hydrocarbons is mainly manifested at the three wavenumbers of $3050-3030 \mathrm{~cm}^{-1}$ (mainly, aromatic ring C-H vibration), $1604-1599 \mathrm{~cm}^{-1}$ (mainly, aromatic ring $\mathrm{C}=\mathrm{C}$ vibration), and $900-700 \mathrm{~cm}^{-1}$, where the vibration of the substituents of the aromatic ring $\mathrm{C}-\mathrm{H}$ structure can be detected. Substituents mainly include those individuated at $870 \mathrm{~cm}^{-1}, 820 \mathrm{~cm}^{-1}$, and $750 \mathrm{~cm}^{-1}$, which can be used as indicators to reflect the degree of polymerization of aromatic nuclei in the molecular structure of coal.

4.2. Aliphatic Hydrocarbons. The $\mathrm{C}-\mathrm{H}$ bond vibrations of aliphatic hydrocarbons in the molecular structure of coal are mainly represented by the stretching vibrations of methyl and methylene groups at $3000-2800 \mathrm{~cm}^{-1}$, in addition to shear vibrations at $1449-1439 \mathrm{~cm}^{-1}$ and $1379-1373 \mathrm{~cm}^{-1}$. Both methyl and methylene structures exist in the coal samples under scrutiny. Methyl and methylene are the active groups involved in the oxidation process of coal, indicating that coal shows conditions for the oxidation reaction in its original state.

4.3. Oxygen-Containing Functional Groups. The absorption bands of oxygen-containing functional groups in the molecular structure of coal are mainly located in the range of $1800-1000 \mathrm{~cm}^{-1}$ and mainly contain hydroxyl, carboxyl, carbonyl, and ether oxygen bonds [15]. Among them, the signal at $1736-1722 \mathrm{~cm}^{-1}$ is the carbonyl stretching vibration of aldehydes, ketones, and acids, that at $1715-1690 \mathrm{~cm}^{-1}$ is the carboxyl vibration, and that at $1330-1060 \mathrm{~cm}^{-1}$ represents the $\mathrm{C}-\mathrm{O}$ vibration. These functional groups are mainly connected to the aromatic macromolecular structure inside the coal. The $\mathrm{O}-\mathrm{H}$ bond mainly exists in three forms: free hydroxyl, intramolecular hydrogen bond, and phenolic alkyd hydroxyl at wavenumbers of $3684-3625 \mathrm{~cm}^{-1}$, $3624-3613 \mathrm{~cm}^{-1}$, and $3550-3200 \mathrm{~cm}^{-1}$, respectively. Because the hydroxyl group is unstable and easily participates in the reaction, it has a greater impact on the coal oxidation reaction. The type and quantity of active groups determine the oxidation reactivity of coal. By testing the changes of active groups in the oxidation process, one can analyze the microscopic process of the oxidation reaction of coal to further determine the oxidation reactivity of coal. The content of hydroxyl and carboxyl groups of the coal sample after immersion in water increased, indicating that the activity of the coal sample becomes stronger after it is immersed in water, which increases the risk of spontaneous combustion.

\section{Oxidation Kinetics}

The coal sample combustion is divided into five stages. The first stage is the adsorption stage $\left(T_{0}-T_{1}\right)$. The weight gain of the coal sample at this stage mainly originates from the physical adsorption of oxygen, which slightly increases the quality of the coal sample, reaching a maximum value at about $50^{\circ} \mathrm{C}$. The second stage is the dehydration stage $\left(T_{1^{-}}\right.$ $T_{2}$ ). At this stage, the coal sample absorbs external heat. The evaporation of water and the desorption of adsorbed gas continually decrease the quality of coal samples, reaching a minimum value at about $130^{\circ} \mathrm{C}$. The third stage is the weight gain stage $\left(T_{2}-T_{3}\right)$. At this stage, the weight gain of all samples is due to the chemical adsorption of oxygen, which significantly increases the coal sample mass. Generally, the sample mass reaches a maximum value at $289^{\circ} \mathrm{C}$. The increased mass at this stage represents the oxygen absorption capacity of the coal. The fourth stage is the oxidation decomposition stage $\left(T_{3}-T_{4}\right)$. At this stage, the quality of coal samples starts to decline, producing large amounts of $\mathrm{H}_{2} \mathrm{O}$ and small molecular organic gases, reaching the ignition temperature of coal at about $380^{\circ} \mathrm{C}$, so the burning of the volatile matter begins, releasing considerable heat. The fifth stage is the oxidation combustion stage $\left(T_{4}-T_{5}\right)$. At this stage, the coal sample is burned, and its quality sharply degrades. A large amount of gas is produced, and a large amount of heat is released until about $740^{\circ} \mathrm{C}$, the coal sample is burned out, and the weight does not change further. Therefore, the monitored temperature range of $30-800^{\circ} \mathrm{C}$ provides real-time monitoring of the entire process of the coal sample burnout from the adsorption stage to the end of the combustion stage.

Coal spontaneous combustion is mainly affected by coal structure and environmental factors [16]. Combined TGFTIR can be used to continuously measure the gas product composition/amount and the coal mass during the combustion process [17]. This technology uses purge gas (nitrogen or air) to introduce the volatile matter or decomposition products generated during the thermal weight loss process into the optical path of the IR spectrometer through a metal pipe and a glass gas pool at a constant temperature $\left(200-250^{\circ} \mathrm{C}\right)[18]$. 
TABLE 1: Main characteristic peaks of the IR spectrum of interest for the present work [13].

\begin{tabular}{|c|c|c|c|}
\hline Spectral peak type & $\begin{array}{c}\text { Peak position } \\
\text { (wavenumber in } \mathrm{cm}^{-1} \text { ) }\end{array}$ & $\begin{array}{l}\text { Functional } \\
\text { group }\end{array}$ & Peak attribution \\
\hline \multirow{3}{*}{ Aromatic hydrocarbons } & $3050-3030$ & $-\mathrm{CH}$ & \multirow{3}{*}{$\begin{array}{c}\text { Aromatic } \mathrm{CH} \text { stretching vibration } \\
\mathrm{C}=\mathrm{C} \text { stretching vibration in aromatic ring } \\
\text { Out-of-plane bending vibration of various substituted aromatic } \\
\text { hydrocarbons }\end{array}$} \\
\hline & $1604-1599$ & $\mathrm{C}=\mathrm{C}$ & \\
\hline & $900-700$ & & \\
\hline \multirow{3}{*}{ Aliphatic hydrocarbon } & $2975-2915$ & $-\mathrm{CH}_{2},-\mathrm{CH}_{3}$ & \multirow{3}{*}{$\begin{array}{c}\text { Asymmetric stretching vibration of methyl and methylene } \\
\text { Symmetrical stretching vibration of methyl and methylene } \\
\text { Methylene shear vibration }\end{array}$} \\
\hline & $2875-2858$ & $-\mathrm{CH}_{2},-\mathrm{CH}_{3}$ & \\
\hline & $1449-1439$ & $-\mathrm{CH}_{2},-\mathrm{CH}_{3}$ & \\
\hline \multirow{5}{*}{$\begin{array}{l}\text { Oxygen-containing } \\
\text { functional group }\end{array}$} & $1736-1722$ & $\mathrm{C}=\mathrm{O}$ & \multirow{5}{*}{$\begin{array}{l}\text { Carbonyl stretching vibrations of aldehydes, ketones, and acids } \\
\text { Carboxyl } \\
\text { Ether bond } \\
\text { Free hydroxyl } \\
\text { Hydrogen bonding between phenol, alcoholic hydroxyl, amino } \\
\text { or water intermolecular association }\end{array}$} \\
\hline & $1715-1690$ & $-\mathrm{COOH}$ & \\
\hline & $1330-1060$ & $\mathrm{C}-\mathrm{O}-\mathrm{C}$ & \\
\hline & $3660-3632$ & $-\mathrm{OH}$ & \\
\hline & $3500-3200$ & $-\mathrm{OH}$ & \\
\hline
\end{tabular}

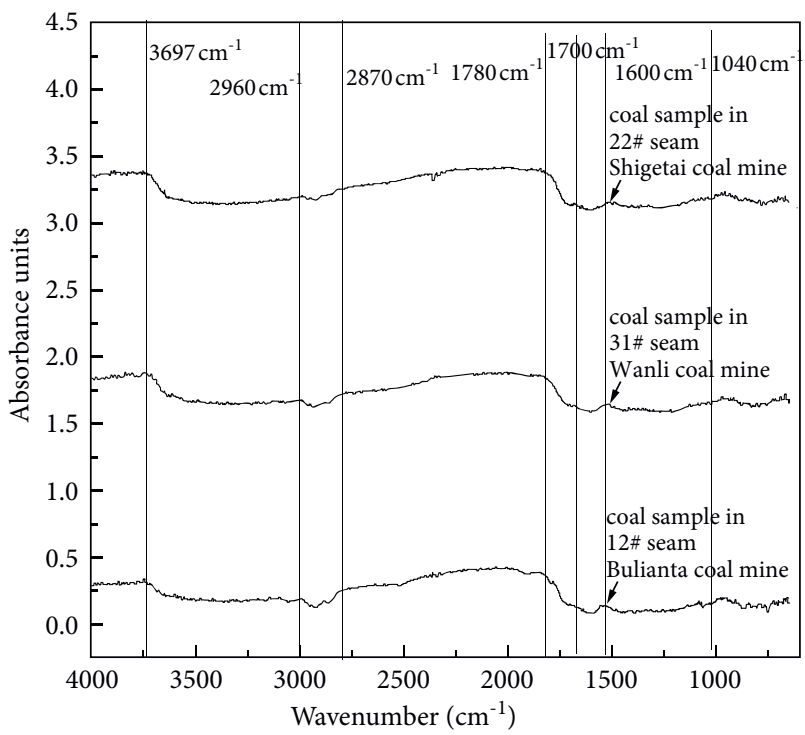

FIGURE 4: Infrared spectra for three coal samples taken from the Shendong mining area.

The experimental system is composed of a STA6000 integrated thermal analyzer combined with a Spectrum 100 infrared spectrometer. The thermogravimetric analyzer and the infrared spectrometer are connected through a TG-FTIR dedicated interface. In order to ensure that the pyrolysis gas escapes from condensation and structural changes, the temperatures of the interface and the gas transmission line were set to $250^{\circ} \mathrm{C}$. The carrier gas was high purity $\mathrm{N}_{2}$. Considering the back-mixing of the escaped gas and the sensitivity of IR detection, the carrier gas flow rate was selected at $90 \mathrm{~mL} / \mathrm{min}$. The coal samples $(10 \mathrm{mg})$ were crushed to a particle size of $0.09-0.106 \mathrm{~mm}$. Figure 5 shows the thermogravimetric analyzer test system. The broken coal samples were placed in the coal sample tank in the thermogravimetric analyzer test system. The samples were analyzed at heating rates of 5,10 , and $15^{\circ} \mathrm{C} / \mathrm{min}$ from 30 to $800^{\circ} \mathrm{C}$ in an atmosphere with air and oxygen concentrations of 5\% and 13\%, respectively.

By analyzing the results of thermogravimetric experiments under different operating conditions, it is found that the trends for different coal samples under different oxygen concentrations and heating rates are basically the same. From the beginning of the experiment to the complete combustion (constant weight of the sample), the oxidation process can be divided into three stages according to the sample weight losses: (i) water loss, (ii) weight increasing oxidation, and (iii) weight loss combustion stage. Figure 6 shows the TG results for the oxidation experiment carried out on the Bulianta 12\# raw coal sample at a heating rate of $10^{\circ} \mathrm{C} / \mathrm{min}$ in air. The water loss stage starts at room temperature and ends at $150-190^{\circ} \mathrm{C}$, while the end of the weight gain oxidation stage is recorded between $280^{\circ} \mathrm{C}$ and $335^{\circ} \mathrm{C}$. In particular, in the weight gain oxidation stage, coal and oxygen undergo physical and chemical adsorption and chemical reactions to form transition intermediate complexes, which results in weight gain in the TG curve. The combustion stage starts from the inflection temperature point at which weight gain turns back to weight loss. The functional groups in coal undergo oxidation reactions to release a large amount of heat and generate corresponding gas products.

The DSC curve characterizes the thermal effect of coal in the process of oxidation and heating. The calculated integrated area represents the heat absorption of the coal oxidation process. Reactions are endothermic reactions before $140^{\circ} \mathrm{C}$, and the temperature range at which the endothermic rate reaches its maximum is $70-75^{\circ} \mathrm{C}$, where the total heat absorption is between $270 \mathrm{~J} / \mathrm{g}$ and $295 \mathrm{~J} / \mathrm{g}$. When the experimental temperature exceeds $70^{\circ} \mathrm{C}$ to $75^{\circ} \mathrm{C}$, as the temperature increases, the heat released by the combined action of coal and $\mathrm{O}_{2}$ is greater than the heat absorbed by the evaporation of water, and the overall heat absorption rate begins to decrease. When the temperature exceeds $140^{\circ} \mathrm{C}$, the reaction is generally exothermic. When the temperature reaches $420^{\circ} \mathrm{C}$ to $475^{\circ} \mathrm{C}$, the exothermic rate reaches its maximum, and the coal begins to undergo a violent oxidation reaction.

\subsection{Effect of Heating Rate and Oxygen Concentration on Coal} Oxidation Process. In the air oxidation process of the same experimental coal sample, the thermogravimetric curve 


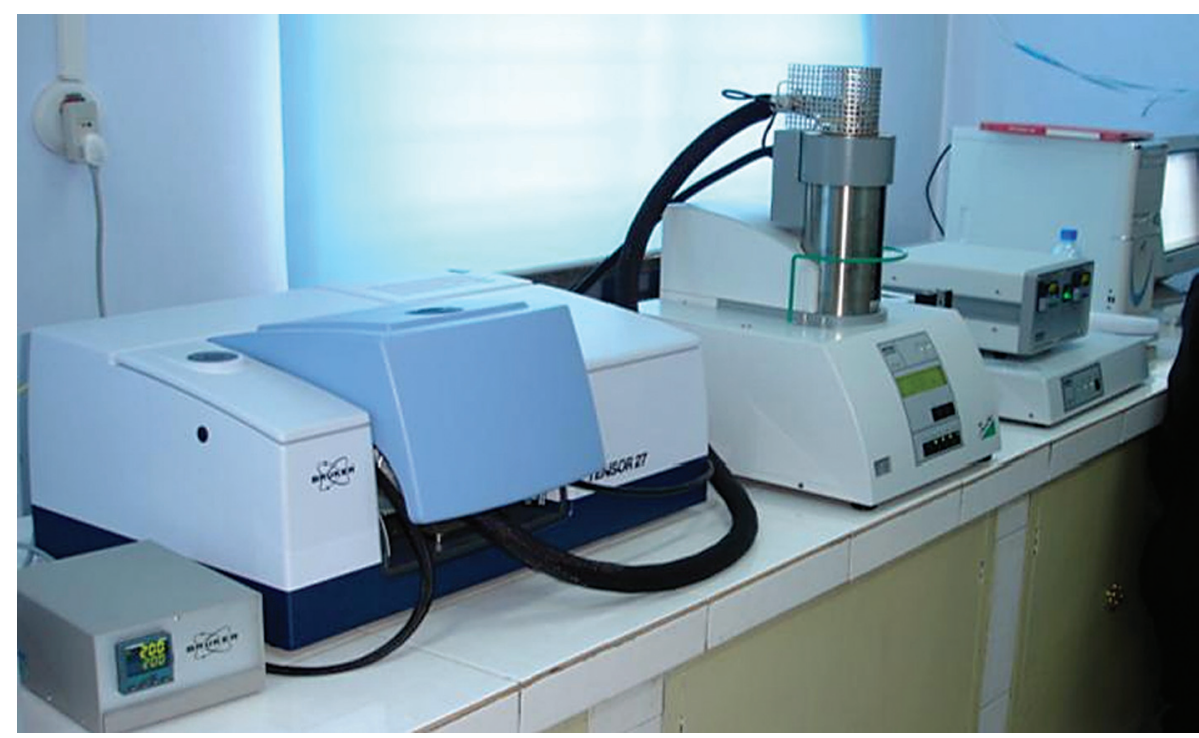

FIGURE 5: Thermogravimetric analyzer test system.

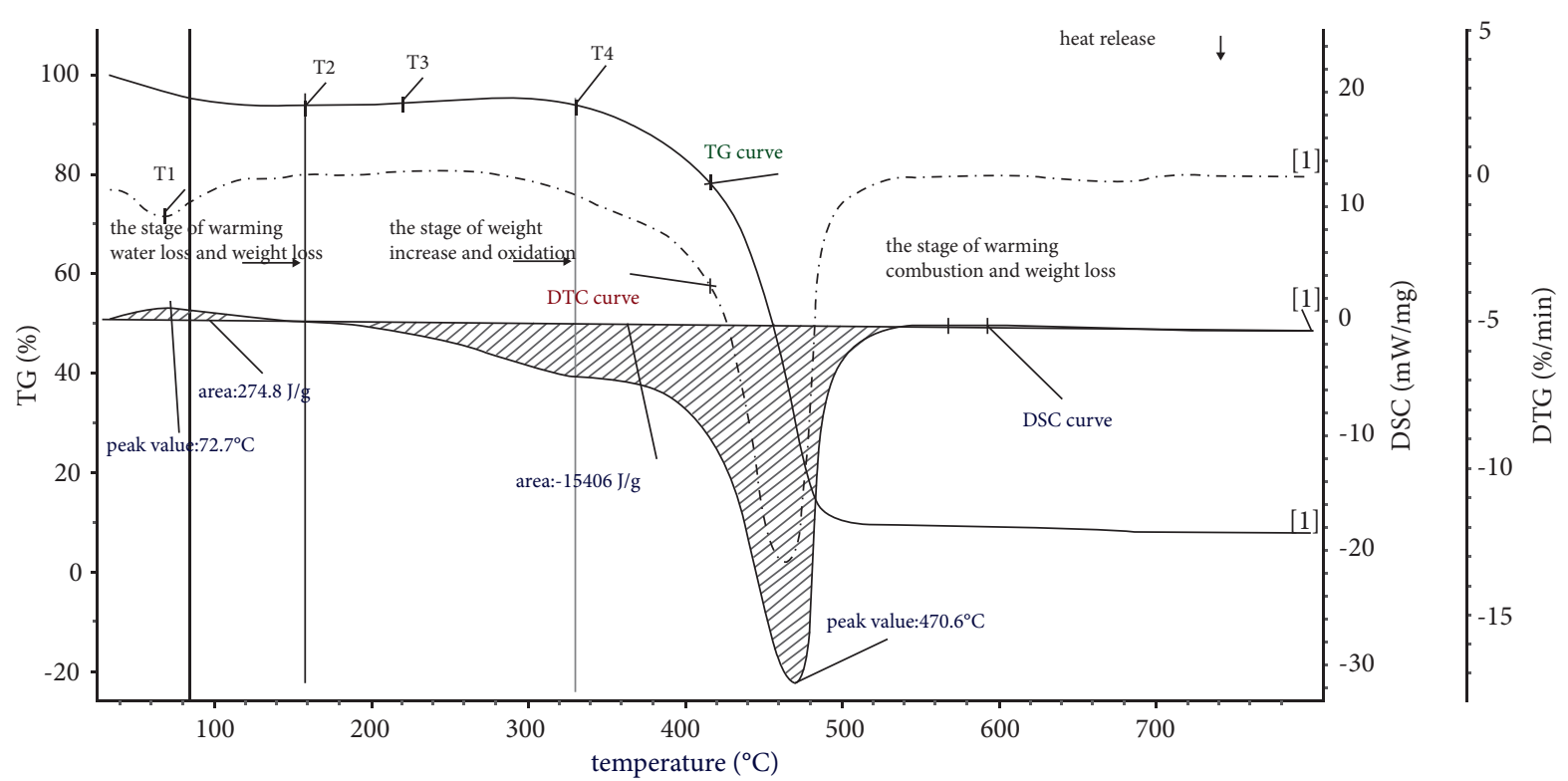

FIgure 6: TG/DTG/DSC results for the Bulianta 12\# raw coal sample at a heating rate of $10^{\circ} \mathrm{C} / \mathrm{min}$ in air.

characteristics when different heating rates are considered are similar. Figure 7 reports, as an example, the TG/DSC curve for the Bulianta 12\# raw coal sample. As the heating rate increases from 5 to $15^{\circ} \mathrm{C} / \mathrm{min}$, the TG/DSC curve shows a hysteresis phenomenon; that is, the curve shifts to the hightemperature direction. This is due to the poor thermal conductivity of coal, and the heating of the external environment cannot directly lead to the rapid heating of the inner coal body. Therefore, compared with the experimental process with a slower heating rate, when the coal sample under the condition of a fast heating rate reaches the same temperature, the degree of internal oxidation reaction of the coal sample is lower, and the weight of the coal sample is higher than that of the coal sample analyzed under a slower heating rate. It can be seen from the DSC curve that, as the heating rate increases, the maximum heat release efficiency has a hysteresis too; that is, the greater the heating rate, the higher the temperature required to reach the maximum heat release, which is consistent with the hysteresis of the TG curve.

Figure 8 reports the TG/DSC curve for the Bulianta 12\# raw coal sample under different $\mathrm{O}_{2}$ concentrations (5-13$21 \%$ ) while the heating rate was $10^{\circ} \mathrm{C} / \mathrm{min}$. It can be seen that there is a hysteresis in both TG and DSC curves when the reaction atmosphere changes from normal air to oxygenlean conditions. Obviously, to burn a coal sample of the same quality, the lower the $\mathrm{O}_{2}$ concentration, the higher the temperature required. 


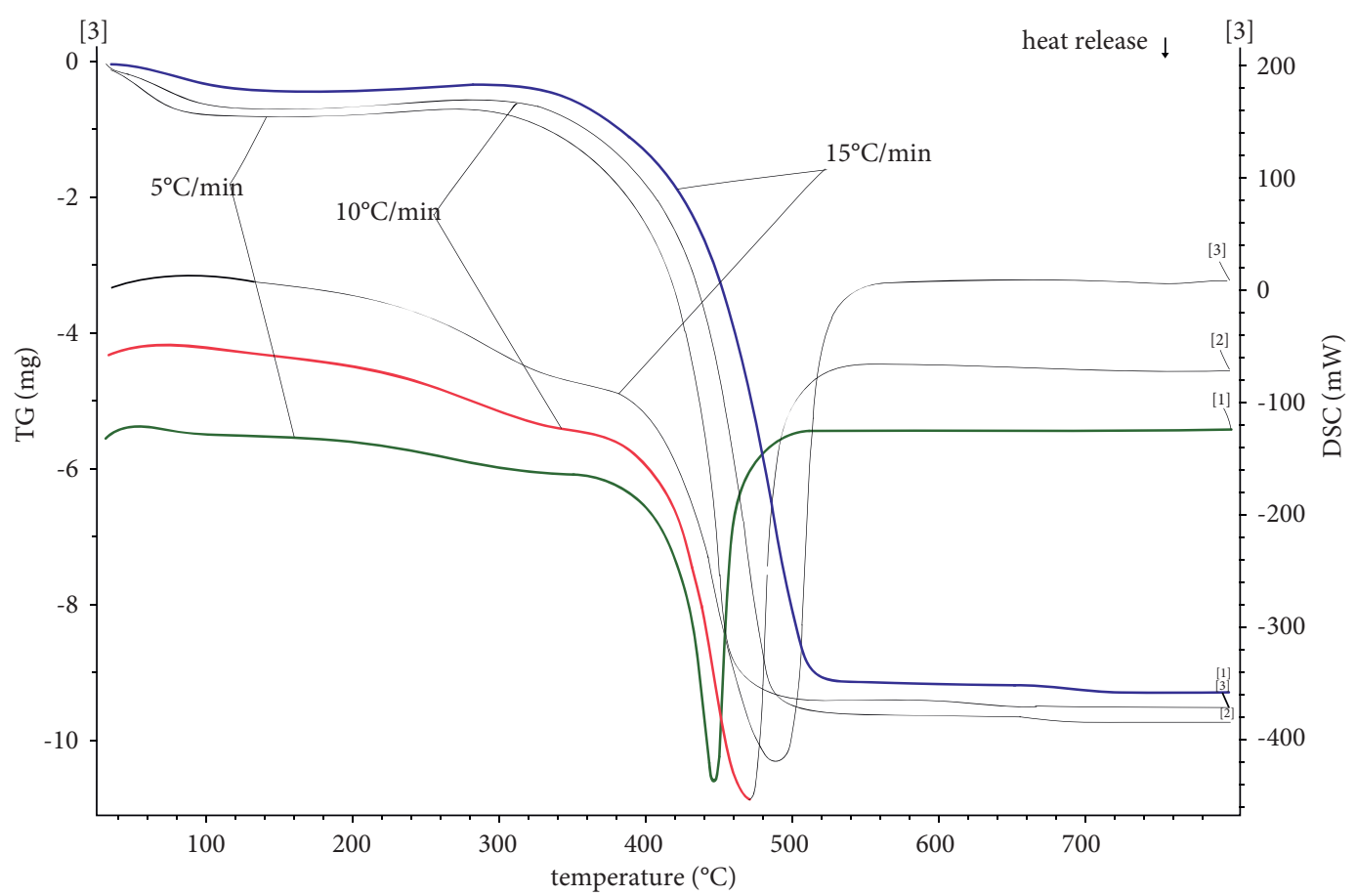

Figure 7: TG/DSC results for the Bulianta 12\# raw coal sample at heating rates of $5-10-15^{\circ} \mathrm{C} / \mathrm{min}$ in air.

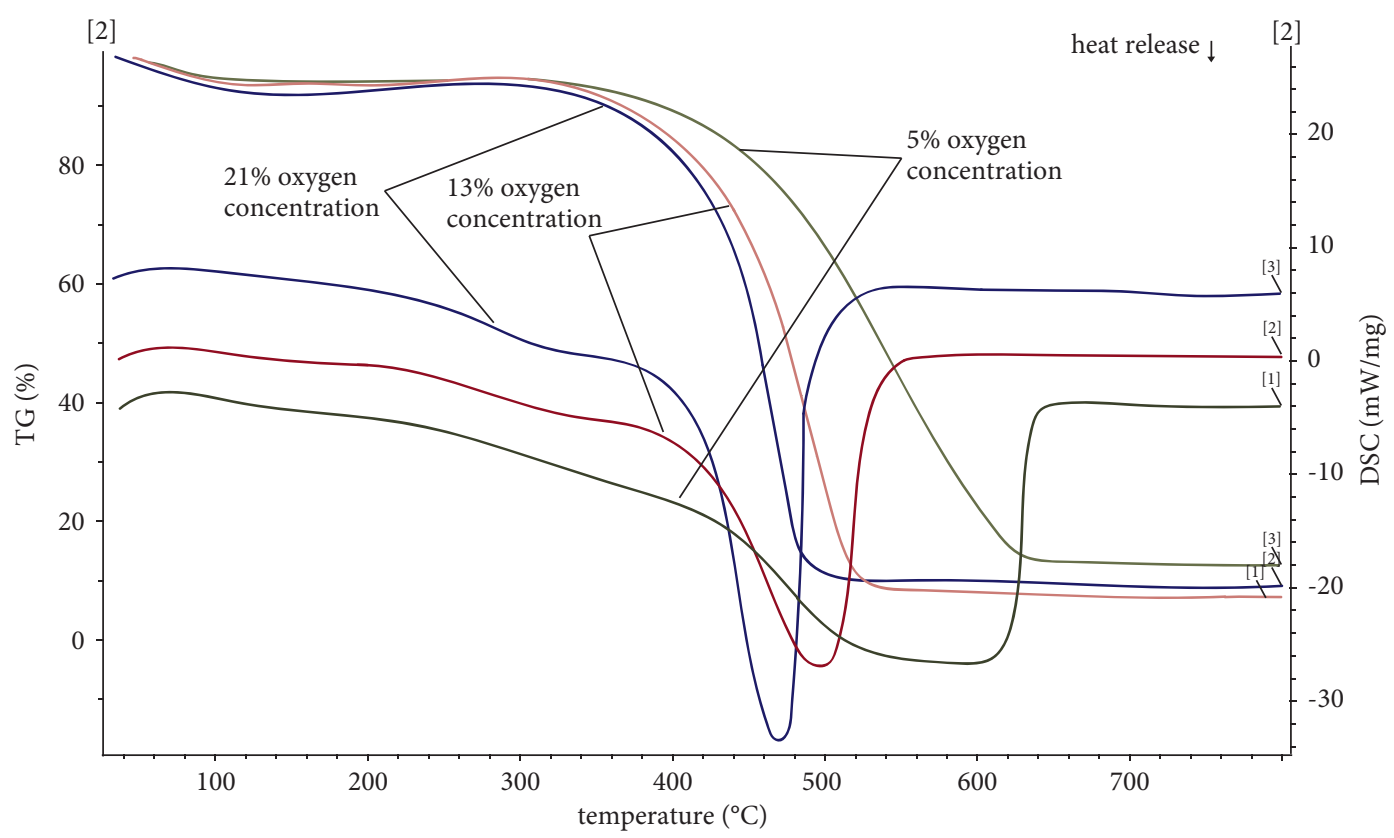

Figure 8: TG/DSC results for the Bulianta 12\# raw coal sample at a heating rate of $10^{\circ} \mathrm{C} / \mathrm{min}$ under $\mathrm{O}_{2}$ concentration of 5-13-21\%.

5.2. Characteristic Temperatures. The characteristic temperatures that can be obtained from TG data under the present experimental conditions are the critical temperature $\left(T_{1}\right)$ corresponding at the maximum weight loss rate in the early water evaporation process, the dry cracking temperature at the lowest point of weight loss $\left(T_{2}\right)$, the activation temperature corresponding at the beginning of weight gain $\left(T_{3}\right)$, and the ignition temperature at the highest weight gain $\left(T_{4}\right)$ [19]. Table 2 lists the characteristic temperatures for the Bulianta 12\# raw coal sample at a heating rate of $10^{\circ} \mathrm{C} / \mathrm{min}$ in air.

5.2.1. Critical Temperature $T_{1}$. The critical temperature corresponds to the maximum point of the weight loss rate in the first weight loss stage. As temperature increases, moisture contained in the coal sample begins to evaporate in 
TABLe 2: Values of characteristic temperatures for the Bulianta $12 \#$ raw coal sample at a heating rate of $10^{\circ} \mathrm{C} / \mathrm{min}$ in air.

\begin{tabular}{lccr}
\hline Critical temperature $T_{1}\left({ }^{\circ} \mathrm{C}\right)$ & Dry cracking temperature $T_{2}\left({ }^{\circ} \mathrm{C}\right)$ & Active temperature $T_{3}\left({ }^{\circ} \mathrm{C}\right)$ & Ignition temperature $T_{4}\left({ }^{\circ} \mathrm{C}\right)$ \\
\hline 68.9 & 158.7 & 220.2 & 330.7 \\
\hline
\end{tabular}

a small amount, and the gas in the coal begins to desorb, which is accompanied by the adsorption and reaction process between coal and $\mathrm{O}_{2}$. When the critical temperature is reached, the difference caused by coal gas desorption and moisture evaporation and oxygen adsorption reaches its maximum. After that, the coal-oxygen recombination reaction accelerates, the $\mathrm{O}_{2}$ absorption rate is faster than the desorption and evaporation rate, and the weight loss rate is reduced. Therefore, the lower $T_{1}$, the higher the coal tendency to spontaneous combustion.

5.2.2. Dry Cracking Temperature $T_{2}$. The dry cracking temperature is the temperature at which the coal sample loses the most weight before burning, that is, the temperature at the end of the initial weight loss phase. After reaching $T_{2}$, coal begins to enter the violent oxidation stage, the types and number of active groups begin to increase sharply, and some active structures in the molecular framework of coal react to produce a certain amount of cracked gas, such as ethylene and ethane. The organic gas that does not occur in raw coal can be used as an indicator for coal oxidation and spontaneous combustion.

5.2.3. Activation Temperature $T_{3}$. The weight gain of the coal sample significantly increases starting from $T_{3}$. With the participation of $\mathrm{O}_{2}$ molecules, part of the active structure in the coal body begins to break bonds and combine with oxygen, generating a large number of active groups and participating in the reaction. The amount of gas produced by the reaction at this stage is generally lower than the amount of coal participating in adsorption and reacting with oxygen.

5.2.4. Ignition Temperature $T_{4}$. At the end of the previous stage, the weight gain of the coal sample reaches a balance with the reaction consumption. The temperature at this time is the ignition temperature of spontaneous combustion. After $T_{4}$, the coal sample begins to enter the violent combustion stage, the reaction process of the active groups in the coal molecular structure enters the rapid reaction consumption stage, and the coal sample begins to enter the obvious weight loss stage.

5.3. Oxidation Kinetics Study. The kinetic parameters of coal oxidation can be used as a basis for characterizing the coal spontaneous combustion tendency. Activation energy has been widely used to measure the difficulty of spontaneous combustion of coal [20]. The oxidation and decomposition of coal is a typical gas-solid reaction. The reaction rate of coal can be expressed by [21]

$$
\frac{\mathrm{d} \alpha}{\mathrm{d} t}=A \exp \left(-\frac{E}{\mathrm{RT}}\right) f(\alpha)
$$

where $\alpha$ is the conversion degree, $A$ the preexponential factor, $E$ the activation energy, $R$ the universal gas constant, $T$ the absolute temperature, $t$ the time, and $f(\alpha)$ the kinetic function used to express the reaction rate at the left-hand side of equation (2). Let us define the heating rate $\beta=\mathrm{d} T / \mathrm{d} t$. Equation (2) now reads

$$
\frac{\mathrm{d} \alpha}{f(\alpha)}=\frac{A}{\beta} \exp \left(-\frac{E}{\mathrm{RT}}\right) \mathrm{d} T .
$$

Equation (3) can be now easily integrated, under the assumption of constant heating rate and assuming $T_{0}$ as the initial temperature, where $g(\alpha)$ is a function related to $f(\alpha)$, and it is called conversion rate function integral:

$$
g(\alpha)=\int_{0}^{\alpha} \frac{\mathrm{d} \alpha}{f(\alpha)}=\frac{A}{\beta} \int_{T_{0}}^{T} \exp \left(-\frac{E}{\mathrm{RT}}\right) \mathrm{d} T
$$

Under the simplifying assumption of negligible value for $T_{0}$, it is

$$
g(\alpha)=\int_{0}^{\alpha} \frac{\mathrm{d} \alpha}{f(\alpha)}=\frac{A}{\beta} \int_{0}^{T} \exp \left(-\frac{E}{R T}\right) \mathrm{d} T
$$

Numerical analysis methods must be used to find an approximate solution. Let $\mu=E / \mathrm{RT}$; then $T=E / R \mu$. Therefore, $\mathrm{d} T=-\left(E / R \mu^{2}\right) \mathrm{d} \mu$, and we get [11]

$$
g(\alpha)=\frac{A}{\beta} \int_{0}^{T} \exp \left(-\frac{E}{\mathrm{RT}}\right) \mathrm{d} T=\frac{A E}{\beta R} \int_{\infty}^{\mu} \frac{-\exp (-\mu)}{\mu^{2}} \mathrm{~d} \mu=\frac{A E}{\beta R} P(\mu),
$$

with the introduction of the function $P(\mu)$. We obtain the Coats-Redfern approximate formula [22]:

$$
\int_{0}^{T} \exp \left(-\frac{E}{\mathrm{RT}}\right) \mathrm{d} T=\frac{E}{R} P(\mu)=\frac{\mathrm{RT}^{2}}{E}\left(1-\frac{2 \mathrm{RT}}{E}\right) .
$$

Combining equations (5) and (7),

$$
g(\alpha)=\int_{0}^{\alpha} \frac{\mathrm{d} \alpha}{f(\alpha)}=\frac{A}{\beta} \frac{\mathrm{RT}^{2}}{E}\left(1-\frac{2 \mathrm{RT}}{E}\right) \exp \left(-\frac{E}{\mathrm{RT}}\right) .
$$

Taking the logarithms, one obtains the Coats-Redfern integral equation [23]:

$$
\ln \left[\frac{g(\alpha)}{T^{2}}\right]=\ln \left[\frac{A R}{\beta E}\left(1-\frac{2 \mathrm{RT}}{E}\right)\right]-\frac{E}{\mathrm{RT}} .
$$

As, in general, $E /(\mathrm{RT})$ is well higher than $1,(1-2 \mathrm{RT} / E)$ is almost $=1$. Therefore, the first term at the right-hand side of equation (9) can be considered, for all practical purposes, constant (under the hypothesis of constant heating rate). 
According to data for our process, the best-fitting $f(\alpha)$ function was the simple $1-\alpha$ (accordingly, $g(\alpha)=-\ln (1-\alpha)$ ), witnessing linear kinetics. Table 3 lists the values for $E$ as obtained from the model application under different operating conditions.

The activation energy increases with the increase in the heating rate (i.e., less likely is the spontaneous coal combustion). In addition, more limited is the effect of $\mathrm{O}_{2}$ concentration on $E$ : this is consistent with the result that the TG curves reporting the effect of different oxygen concentration values on coal spontaneous combustion show little changes during the $\mathrm{O}_{2}$ absorption and weight gain stage.

5.4. Gas Product Analysis. Figure 9 shows the IR spectra of different gas products obtained in air with a heating rate of $10^{\circ} \mathrm{C} / \mathrm{min}$. Upon the occurrence of air oxidation of coal samples, gas products have clear IR characteristic peaks. Taking the wavenumber as the abscissa $\left(4000-400 \mathrm{~cm}^{-1}\right)$ and the normalized absorbance $(0-1)$ as the ordinate, the infrared spectrum of the total gas product at a certain time can be obtained. Then, the functional groups can be analyzed. Taking time $(0-40 \mathrm{~min})$ or equivalently temperature $\left(0-1000^{\circ} \mathrm{C}\right)$ as the abscissa and absorbance $(0-1)$ as the ordinate, the concentration of a specific gas component can be obtained.

Due to the time lag between the IR spectrum and TG curve, the starting point of IR gas generation, the maximum gas peak, and the absorbance returning to the baseline are selected as references to determine the mutual relationship between TG temperature and FTIR time. It can be found that the gas product yield significantly changes during the oxidation of coal samples, and the vibration intensity of $\mathrm{CO}_{2}$ gas at $2400-2300 \mathrm{~cm}^{-1}$ is the clearest signal for this effect. It can be seen that the pyrolysis gas of coal oxidation is mainly produced in the range $19-50 \mathrm{~min}$. Figure 10 shows, for the Bulianta 12\# raw coal sample, FTIR spectra obtained at the critical temperatures as listed in Table 2, plus the spectrum at $33.7^{\circ} \mathrm{C}$. According to the characteristic absorption peaks of the IR spectra of different standard gases (as shown in Figure 11), the composition and content of the gas in the oxidation product can be inferred.

During the oxidation process, a C-O stretching vibration peak can be seen at $2400-2221 \mathrm{~cm}^{-1}$. The wavenumbers $2356.59 \mathrm{~cm}^{-1}$ and $770-660 \mathrm{~cm}^{-1}$ indicate the presence of $\mathrm{CO}_{2}$. The source of $\mathrm{CO}_{2}$ is mainly the fracture and reforming of $\mathrm{C}=\mathrm{O}$ and $-\mathrm{COOH}$. There are tiny hydroxyl vibration absorption peaks at $3774-3513 \mathrm{~cm}^{-1}$ and $1900-1300 \mathrm{~cm}^{-1}$, indicating the production of $\mathrm{H}_{2} \mathrm{O}$. There is a $\mathrm{C}=\mathrm{O}$ stretching vibration peak at $1860-1600 \mathrm{~cm}^{-1}$, indicating that aldehydes and organic acids are produced. As the temperature continues to rise to $325^{\circ} \mathrm{C}$, it can be seen from the spectrum that there are two tiny $\mathrm{CO}$ characteristic peaks near $\mathrm{CO}_{2}$ at $2240-2100 \mathrm{~cm}^{-1}$. At the same time, in the range of $1580-1280 \mathrm{~cm}^{-1}$, an absorption peak $\left(1524 \mathrm{~cm}^{-1}\right)$ appears, which is the stretching vibration of the ether bond. There is no $\mathrm{C}-\mathrm{H}$ asymmetric stretching vibration at $3000-2700 \mathrm{~cm}^{-1}$, indicating almost no $\mathrm{CH}_{4}$ in the product; there is no obvious
TABLE 3: Values of activation energy for the Bulianta 12\# raw coal sample as obtained from kinetic modelling under different operating conditions.

\begin{tabular}{lcc}
\hline $\mathrm{O}_{2}$ concentration $(\%)$ & Heating rate $\left({ }^{\circ} \mathrm{C} / \mathrm{min}\right)$ & $E(\mathrm{~kJ} / \mathrm{mol})$ \\
\hline \multirow{3}{*}{5} & 5 & 83.001 \\
& 10 & 74.779 \\
& 15 & 126.589 \\
\hline \multirow{3}{*}{13} & 5 & 77.59 \\
& 10 & 86.64 \\
& 15 & 107.151 \\
\hline \multirow{3}{*}{21} & 5 & 77.59 \\
& 10 & 85.036 \\
\hline
\end{tabular}

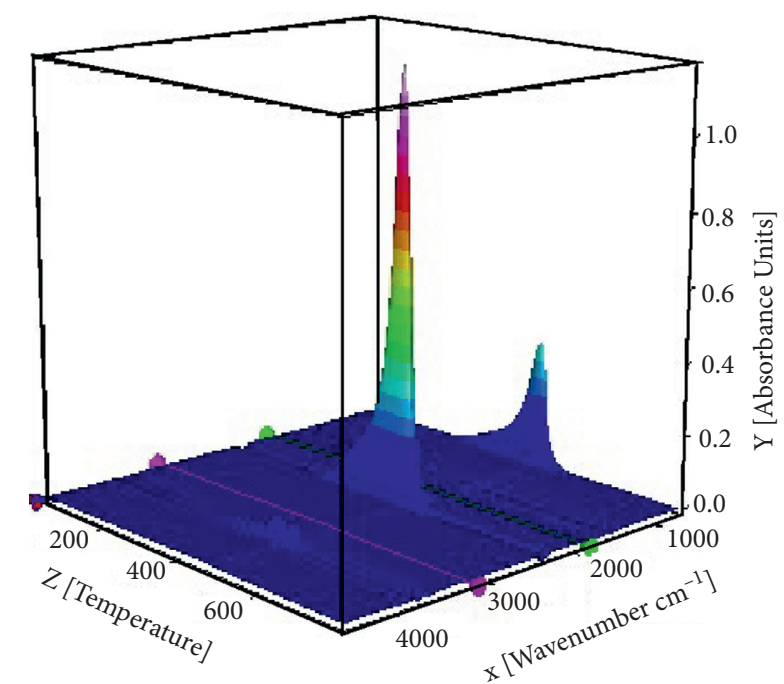

FIGURE 9: FTIR spectrum of gas products for the Bulianta 12\# raw coal sample (air, heating rate $=10^{\circ} \mathrm{C} / \mathrm{min}$ ).

absorption peak at $1189 \mathrm{~cm}^{-1}$, that is, hydroxyl stretching vibration, indicating that there is no alcohol or phenolic compound in the product.

According to the Lambert-Beer law, the higher the gas content, the more evident the corresponding characteristic peak, and the absorption peak area is proportional to the gas content. Therefore, the change of the gas content in the oxidation process can be reflected by the change of absorbance, and then the trend of the content of the gas product with the extension of the oxidation time can be obtained. As shown in Figure 12, where the abscissa represents the temperature, and the ordinate represents the vibration intensity of the IR spectrum peak, in the temperature range of the water loss and weight loss stage and oxygen absorption and weight gain stage, the main gas products are $\mathrm{CO}$ and moisture, and both increase in content with the increase in temperature. Moreover, the amount of $\mathrm{H}_{2} \mathrm{O}$ produced is lower than that of $\mathrm{CO}$, as well as that of ethers and aldehydes. During the coal combustion stage at $400-450^{\circ} \mathrm{C}$, the $\mathrm{H}_{2} \mathrm{O}$ growth rate is the largest, and coal combines with $\mathrm{O}_{2}$ and quickly reacts, producing a large amount of $\mathrm{CO}_{2}$ and $\mathrm{CO}$ gas and a large amount of $\mathrm{H}_{2} \mathrm{O}$, ethers, and aldehydes gas products. 


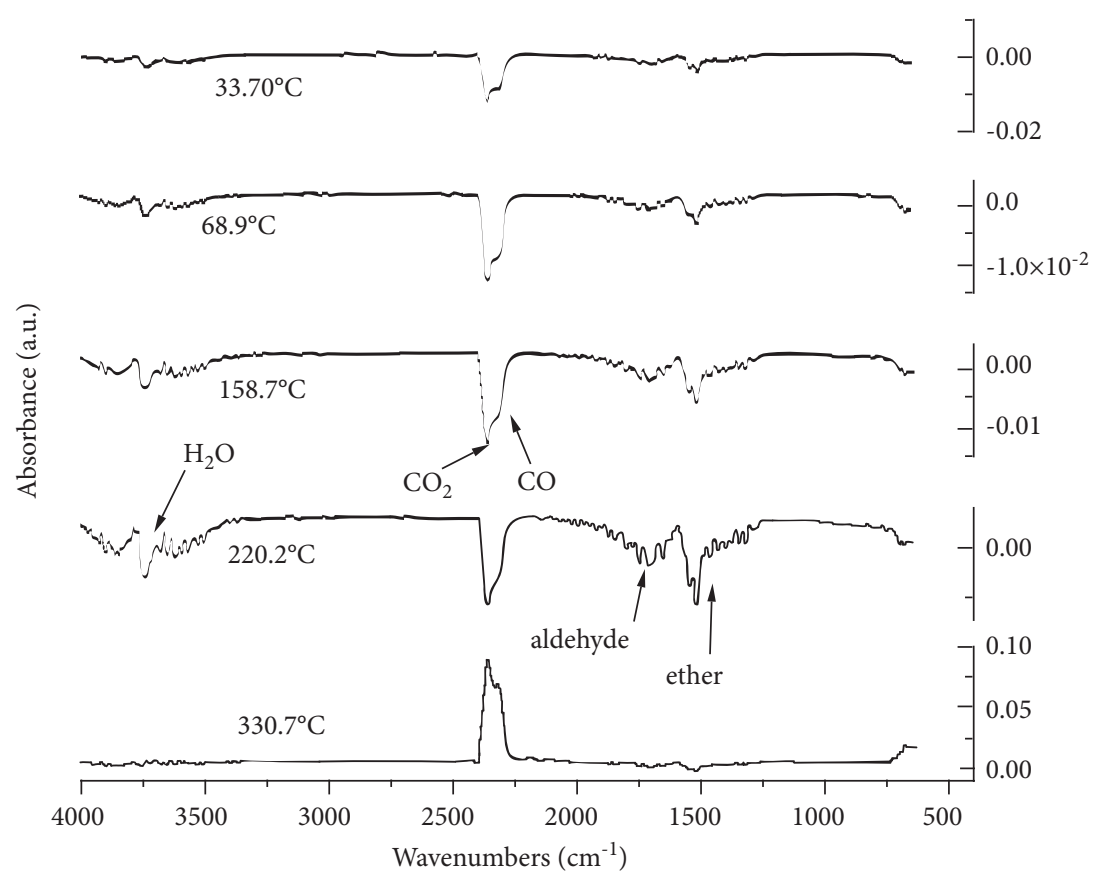

FIgURE 10: IR spectra of gas products for the Bulianta 12\# raw coal sample at characteristic temperatures (cf. Table 2).

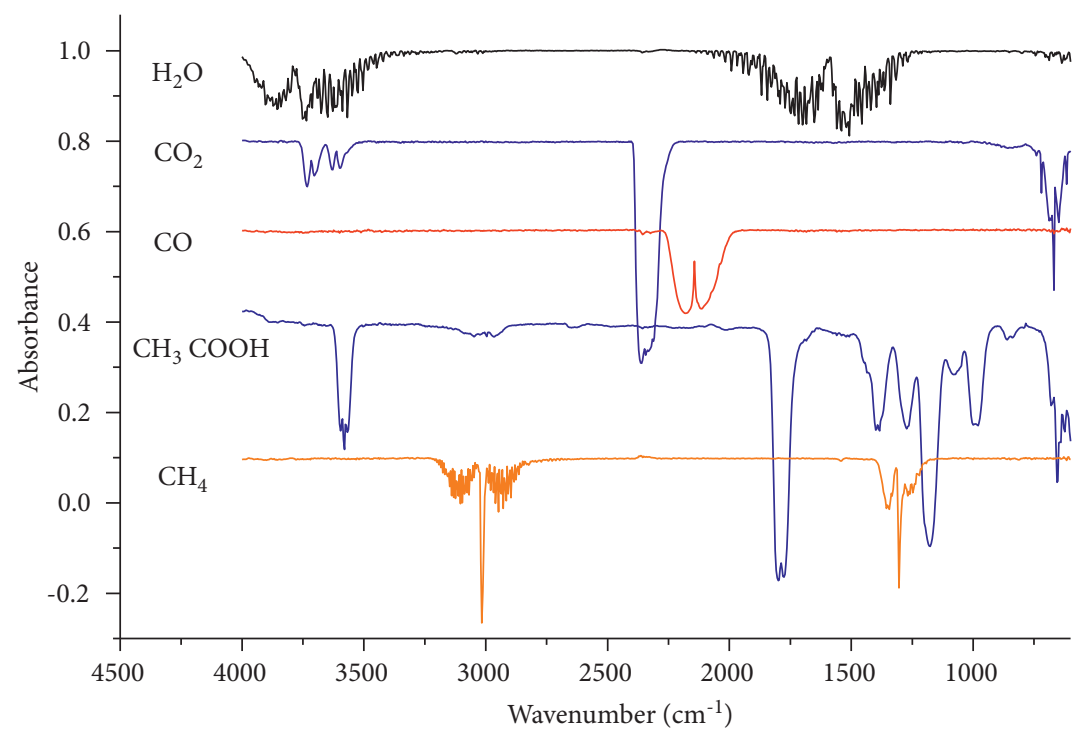

FIGURE 11: Infrared spectra of reference standard gases.

\section{Heat Release of Coal Samples with Different Moisture Content}

The spontaneous combustion of coal is a very complex process characterized by physical and chemical changes [24]. Among them, physical changes include gas adsorption, desorption, evaporation and condensation of moisture, heat conduction, heating of coal, and loosening of structure. Chemical changes include the chemical adsorption and chemical reaction of various active structures on coal surface molecules with $\mathrm{O}_{2}$, generating oxygen-containing groups and gases, accompanied by thermal effects (exothermic and endothermic). Due to the chemical reactions, the internal cross-linking bonds of coal macromolecules are redistributed, which changes in the physical and chemical properties of coal that further affect the process of coal-oxygen recombination. This process of coal-oxygen has exothermic characteristics that vary with temperature, coal porosity, and surface area in contact with air. In this work, mixed coal samples of different particle sizes are investigated, in terms of spontaneous combustion characteristics such as $\mathrm{O}_{2}$ consumption and oxidation exothermic intensity at different temperatures. 


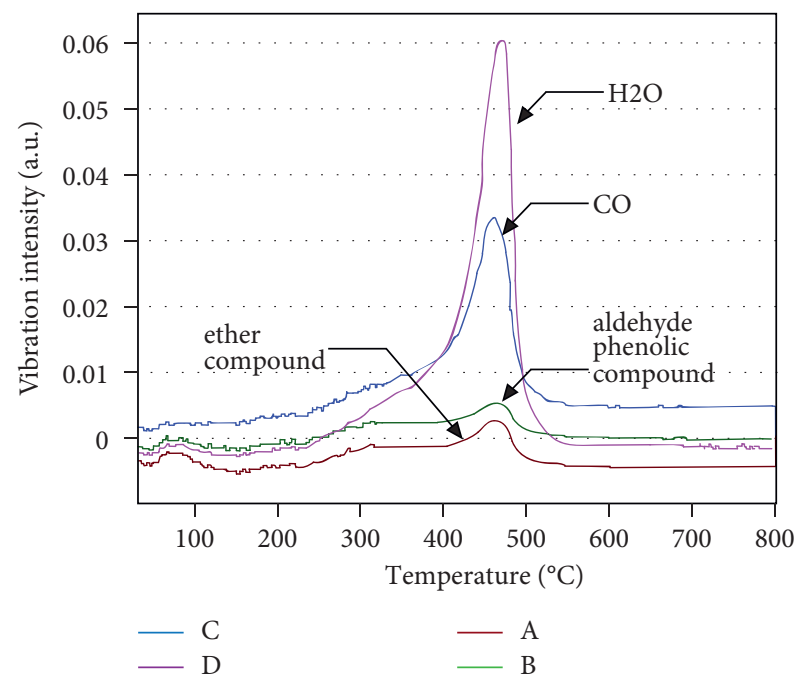

FIGURE 12: Vibration intensity versus temperature for gaseous products during the combustion of the Bulianta $12 \#$ raw coal sample.

6.1. Experimental Device and Operating Conditions. The experimental device is based on an oil bath temperatureraising instrument developed by the Xi'an University of Science and Technology. The system (Figure 13) is composed of four major parts: intelligent temperature control oil bath, gas supply, cooling, gas collection, and analysis [25]. The length, width, and height of the oil bath tank are $1 \mathrm{~m} \times 0.5 \mathrm{~m} \times 0.5 \mathrm{~m}$. The tank wall is made of a double-layer stainless steel shell, and the inner is filled with heat preservation materials. The inner diameter of the test tube containing the coal sample is $5 \mathrm{~cm}$, the length is $60 \mathrm{~cm}$, and the coal loading inventory is about $1 \mathrm{~kg}$. Coal is crushed and then put into the test tube, sealed at both ends, and located into the heavy oil bath with a boiling point higher than $200^{\circ} \mathrm{C}$. The digital temperature control instrument is used to control and track the temperature of the electric heating tube and thermocouple so that the temperature in the oil bath rises according to the set procedure. An agitator is installed on one side of the oil bath to ensure a uniform temperature in the oil bath. Copper inlet and outlet pipes at both ends of the coal sample test tube are present. The inlet pipe is immersed in the oil bath to ensure that air is fully preheated before entering the test tube. The air enters the test tube after passing through an oil-free air compressor and a glass rotor flow meter, and the airflow rate is set to $120 \mathrm{~mL} / \mathrm{min}$. The outflowing gas is sent to a SP-3430 high-precision gas chromatograph to analyze its composition.

The moisture content of the Bulianta 12\# raw coal sample is $9.24 \%$. The raw coal sample was crushed and sieved to obtain samples belonging to the particle size ranges: $0-0.9 \mathrm{~mm}, 0.9-3 \mathrm{~mm}, 3-5 \mathrm{~mm}, 5-7 \mathrm{~mm}$, and $7-10 \mathrm{~mm}$. For each size range, $200 \mathrm{~g}$ were taken and mixed to have a coal sample of $1 \mathrm{~kg}$. Water was sprayed, and the coal sample was allowed to fully absorb it. Coal samples with a moisture content of $4.12 \%, 6.50 \%, 9.24 \%, 11.71 \%, 14.13 \%$, and $16.05 \%$ were prepared and then placed in a vacuum drying oven at $40^{\circ} \mathrm{C}$ for $24 \mathrm{~h}$. Then, the temperature programmed experiments (see Figure 13) were carried out.
6.2. CO Production Rate under Different Moisture Content. Figure 14 shows the effect of temperature on the rate of CO production under different water content. Although the moisture content in coal is different, the curve of oxygen consumption rate with temperature is basically the same. Moreover, the entire oxidation spontaneous process is divided into three stages; in each stage, the influence of moisture on the spontaneous combustion of coal is different. In the early stage of coal spontaneous combustion (up to about $80^{\circ} \mathrm{C}$ ), when the coal body just starts to oxidize, the chemical reaction rate is relatively slow and the $\mathrm{O}_{2}$ consumption is low. When the temperature exceeds $80^{\circ} \mathrm{C}$, the rate of $\mathrm{O}_{2}$ consumption significantly increases, and the spontaneous combustion reaction of coal accelerates. When the coal body temperature reaches about $120^{\circ} \mathrm{C}$, the $\mathrm{O}_{2}$ consumption rate remains basically unchanged. Figures 15-17 illustrate the results separately for the three stages: $35-80^{\circ} \mathrm{C}, 90-110^{\circ} \mathrm{C}, 120-170^{\circ} \mathrm{C}$, respectively. Before reaching the critical temperature $\left(60-80^{\circ} \mathrm{C}\right.$ ) (i.e., during the low-temperature oxidation stage), moisture promotes oxygen consumption. This is because the initial coal oxidation is mainly a free radical chain reaction, which requires the participation of water to proceed. The small amount of heat generated will dissociate water to produce $\mathrm{H}^{+}$ions, which can form a film on the surface of the coal body, beneficial to the absorption of oxygen molecules. After the critical temperature is exceeded, the oxidation reaction rate accelerates, and coal spontaneous combustion enters the rapid oxidation stage. At this time, $\mathrm{H}^{+}$ions are not stable, and the presence of moisture will absorb the heat generated during the oxidation of coal, thereby delaying the increase in temperature. Therefore, here moisture has an inhibitory effect on coal spontaneous combustion. When the coal body temperature reaches $110^{\circ} \mathrm{C}$, the moisture evaporates, and the coal spontaneous combustion reaches the stage of full development. It can be seen from Figure 16 that the lower the moisture content in the coal, the earlier the spontaneous combustion. At the same time, the higher the moisture content in the original coal sample, the greater the $\mathrm{O}_{2}$ consumption rate after the moisture has evaporated; that is, the coal body is more prone to spontaneous combustion. This is mainly due to the following: (i) on one hand, more pores are formed in the coal body after water evaporates, which increases the contact area between the coal body and oxygen and makes the coal body more prone to spontaneous combustion, and (ii) on the other hand, after water evaporates, the physical properties of the coal are changed, the thermal conductivity of the coal is reduced, the heat storage is easier, and the activation energy of the coal is reduced, making the coal easier to oxidize and spontaneously combust.

It can be seen that the moisture in coal is a "doubleedged sword." In the low-temperature oxidation stage, the presence of moisture will increase the absorption of oxygen. In the rapid oxidation stage, moisture can effectively delay the oxidation of coal. But, when water evaporates, the coal sample with more initial water content will have a faster oxidation reaction and greater risk of spontaneous combustion. 


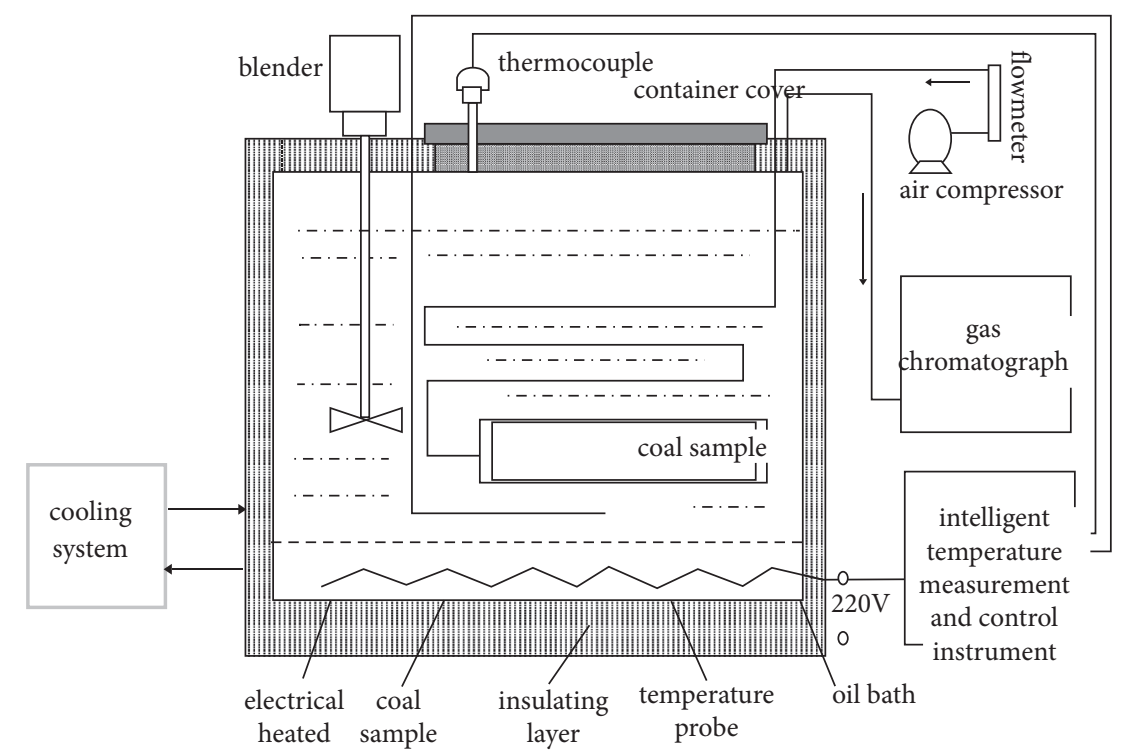

FIgURE 13: Schematic diagram of the temperature programmed oil bath experimental device.

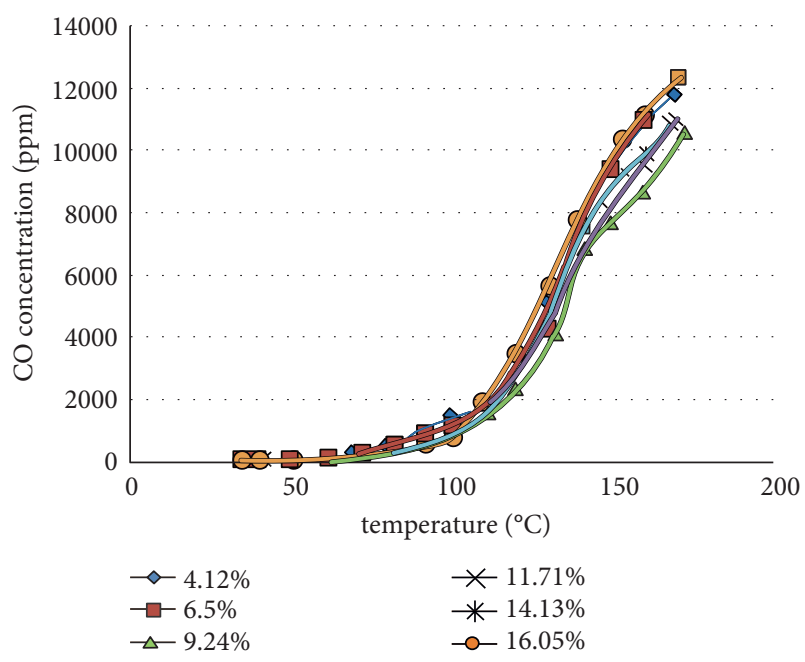

FIGURE 14: Evolution of CO concentration, as an index of coal spontaneous combustion, for samples with different moisture content in the whole temperature range investigated.

\section{Discussion}

Through this research, the oxidation mechanism of waterleaching coal in the northern part of the Shendong mining area and the essential causes and mechanisms of spontaneous combustion have been investigated. The main results are now discussed.

(1) Due to the effect of dissolving inorganic substances and swelling coal body cracks, the specific surface area of the coal sample after water immersion is significantly increased, and the pore structure is more developed, which increases the chance of coal contact with $\mathrm{O}_{2}$ molecules. On the one hand, this favours the adsorption of oxygen. On the other hand, the chance of reacting with oxygen is

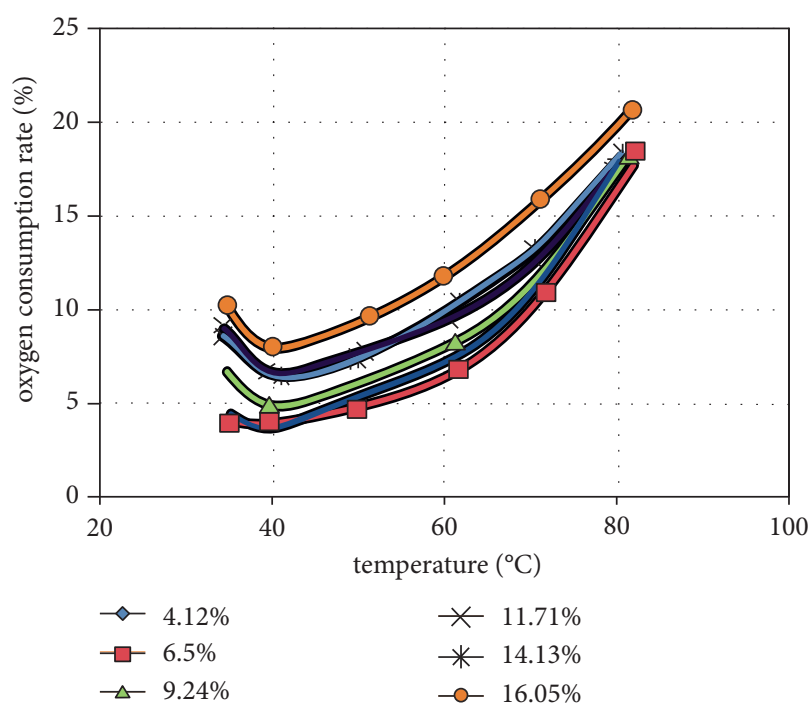

Figure 15: Evolution of $\mathrm{CO}$ concentration, as an index of coal spontaneous combustion, for samples with different moisture content in the temperature range of $35-80^{\circ} \mathrm{C}$.

correspondingly increased, which increases the risk of spontaneous combustion.

(2) The content of hydroxyl and carboxyl groups in the coal sample dried after immersion in water has increased, indicating that the activity of the coal sample becomes stronger after the coal sample is immersed in water, which increases the risk of coal spontaneous combustion as well.

(3) The influence of $\mathrm{H}^{+}$ions produced by water separation and decomposition favours the spontaneous combustion reaction of coal. When water and coal come into contact, the heat of the solution is generated. Therefore, starting from this mechanism, the water-immersed coal sample can be treated with an 


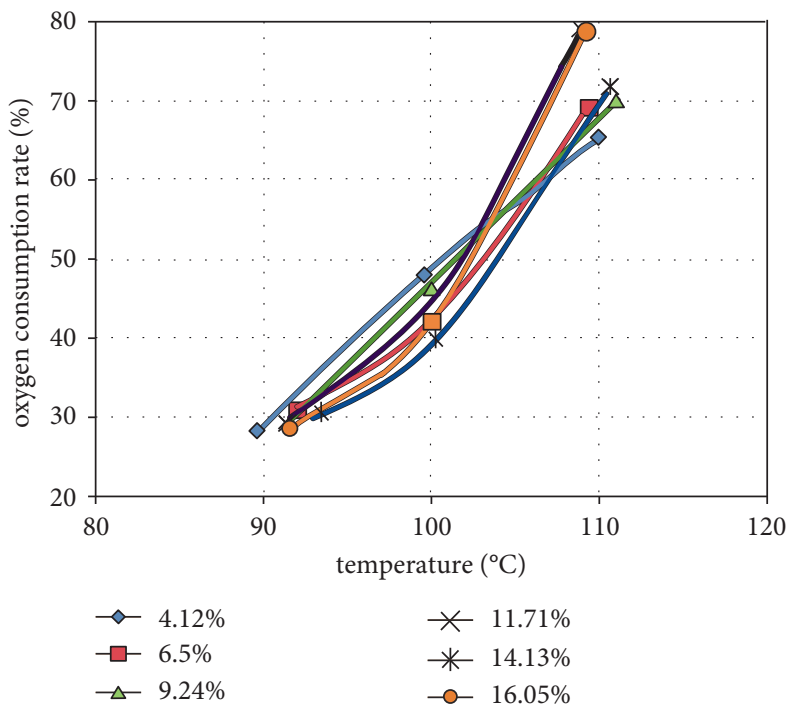

FIGURE 16: Evolution of $\mathrm{CO}$ concentration, as an index of coal spontaneous combustion, for samples with different moisture content in the temperature range of $90-110^{\circ} \mathrm{C}$.

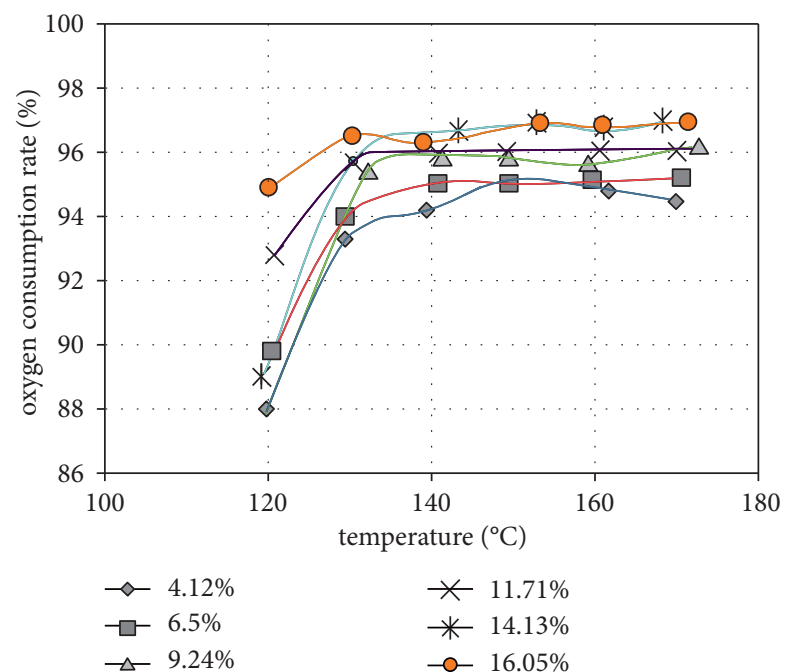

Figure 17: Evolution of CO concentration, as an index of coal spontaneous combustion, for samples with different moisture content in the temperature range of $120-170^{\circ} \mathrm{C}$.

alkaline inhibitor (such as calcium hydroxide) to delay its spontaneous combustion by neutralizing the $\mathrm{H}^{+}$ions produced by the separation and decomposition of water. The use of plugging materials such as colloids to cover and block the surface and pores of the coal body can be a means to reduce the expansion of the pores caused by the evaporation of water and reduce the contact between the coal body and oxygen.

(4) The specific heat of moisture is larger than that of coal. The water-bearing coal sample has a slower heating rate due to its larger specific heat. When water evaporates, the specific heat of the coal is greatly reduced. Under the oxidation heat release, the temperature of the coal sample is greatly increased compared with that of the water-bearing coal sample, thereby increasing the heating rate of the coal sample.

(5) During the spontaneous combustion process of coal samples, the amount of generated $\mathrm{CO}$ and $\mathrm{CH}_{4}$ are higher than those observed for raw coal samples without water immersion treatment. It can be seen that the water-immersed coal sample shows a stronger spontaneous combustion hazard than the original coal sample when the moisture evaporates.

Before the critical temperature of the coal sample is reached $\left(<60-80^{\circ} \mathrm{C}\right)$, moisture will promote the consumption of oxygen. The greater the moisture, the greater the $\mathrm{O}_{2}$ consumption rate. After the critical temperature is exceeded, moisture inhibits the spontaneous combustion of coal. Higher moisture content results in stronger inhibition. This is mainly because the water in coal samples will dissociate to produce $\mathrm{H}^{+}$ions. These $\mathrm{H}^{+}$ions can form a film on the surface of the coal, which favours the absorption of oxygen molecules. However, when the temperature exceeds the critical temperature, the oxidation reaction rate accelerates, and the spontaneous combustion of coal enters the rapid oxidation stage. At this time, $\mathrm{H}^{+}$ions are no more stable. In addition, too much moisture will absorb the heat generated during the oxidation of coal, thereby delaying the rise in temperature. Therefore, the moisture in coal is a "doubleedged sword." In the low-temperature oxidation stage of coal, the presence of moisture will increase the absorption of oxygen by the coal; in the rapid oxidation stage, moisture can effectively delay the oxidation of coal; however, when moisture evaporates, the coal sample with more initial moisture will have a faster oxidation reaction and show greater risk of spontaneous combustion. Under different moisture content, the production of $\mathrm{CO}, \mathrm{CO}_{2}, \mathrm{CH}_{4}, \mathrm{C}_{2} \mathrm{H}_{4}$, and $\mathrm{C}_{2} \mathrm{H}_{6}$ is affected by moisture as long as temperature 
changes. During the whole process of spontaneous combustion, oxidation, and heating, the production of such species for the coal sample after water immersion treatment is basically higher than that for the raw coal sample without water immersion treatment. For example, when the coal temperature is $70^{\circ} \mathrm{C}$, the $\mathrm{CH}_{4}$ concentration value is $2.656 \mathrm{ppm}$, and when the coal temperature reaches $100^{\circ} \mathrm{C}$, the $\mathrm{CH}_{4}$ concentration value is $3.583 \mathrm{ppm}$. In contrast, for the water-immersed coal sample, after the water evaporates $\left(>100^{\circ} \mathrm{C}\right.$ ), the amount of $\mathrm{CH}_{4}$ produced is significantly higher than that for the original coal sample. The coal sample after water immersion, when the moisture evaporates, exhibits a greater risk of spontaneous combustion than raw coal. Therefore, the amount of production of $\mathrm{CO}, \mathrm{CO}_{2}, \mathrm{CH}_{4}$, $\mathrm{C}_{2} \mathrm{H}_{4}$, and $\mathrm{C}_{2} \mathrm{H}_{6}$ can be used to obtain the optimal moisture content by looking at coal spontaneous combustion. The moisture content of $16.05 \%$ is most favours coal spontaneous combustion.

\section{Conclusions}

(1) The specific surface area of the Bulianta 12\# raw coal sample $\left(8.342 \mathrm{~m}^{2} / \mathrm{g}\right)$ is calculated based on the BET theory by the gas adsorption method. This great specific surface area results in a great chance of coal to contact with oxygen molecules. On the one hand, this favours the adsorption of oxygen. On the other hand, the chance of reacting with oxygen is correspondingly increased, thereby increasing the risk of spontaneous combustion.

(2) A silk charcoal structure can be found in the experimental coal samples, which is striped. Because the cracks in the silk charcoal structure are fully developed, this leads to the observed large specific surface area of coal. The pores of the coal sample are well developed, and the connectivity between the pores is good, the micron-scale cracks are well developed, and the cracks and pores are interconnected. The specific surface area of different coal samples is different, which is related to the development of pores and cracks, which will cause differences in the amount of oxygen adsorption and affect the early oxidation upon coal spontaneous combustion. When there are more pores and cracks, and a larger specific surface area, this determines more opportunities for contact with oxygen, and a larger amount of oxygen adsorption, which favours early oxidation and heat release. Therefore, from the perspective of the effect of porous microstructure on oxygen adsorption, the coal samples show a high tendency to spontaneous combustion.

(3) The coal samples dried in water are affected by the combined effects of water specific heat, enlarged swelling cracks, and water dissociation in $\mathrm{H}^{+}$ions. Compared with raw coal, the water-treated samples show a stronger oxidation heating rate and a stronger tendency to spontaneous combustion.
(4) Regarding the appearance temperature of $\mathrm{CO}$ in the coal oxidation process (about $35^{\circ} \mathrm{C}$ ), the moisture content has basically no effect. As far as the sudden change temperature and the second sudden change temperature related to $\mathrm{CO}$ are concerned, the temperature is the lowest when the moisture content in the sample is $6.5 \%$, and the sudden change temperature related to $\mathrm{CO}$ under other moisture content values is about $70^{\circ} \mathrm{C}$. When the moisture content is $9.24 \%$, the second change temperature related to $\mathrm{CO}$ is $91.54^{\circ} \mathrm{C}$. When the moisture content increases, this temperature is about $100^{\circ} \mathrm{C}$. When the moisture content increases from $4.12 \%$ to $9.24 \%$, the appearance temperatures for $\mathrm{C}_{2} \mathrm{H}_{6}$ and $\mathrm{C}_{2} \mathrm{H}_{4}$ both gradually increase, which means that moisture has an inhibitory effect on the formation of these two gases. However, when the moisture content exceeds 9.24\%, the effect becomes insignificant, and the appearance temperature of the two gases remains basically unchanged: for $\mathrm{C}_{2} \mathrm{H}_{6}$, it is about $100^{\circ} \mathrm{C}$ and for $\mathrm{C}_{2} \mathrm{H}_{4}$, it is about $92^{\circ} \mathrm{C}$. When the moisture content is $6.5 \%$, the critical temperature and dry cracking temperature upon coal spontaneous combustion are the lowest. Under other moisture content values, no matter the moisture content increases or decreases, the critical temperature is maintained at $65-75^{\circ} \mathrm{C}$, and the dry cracking temperature is basically between 95 and $105^{\circ} \mathrm{C}$.

(5) Regardless of the moisture content, the critical temperature is between $65^{\circ} \mathrm{C}$ and $75^{\circ} \mathrm{C}$, and the temperature of the remaining coal in the goaf should be prevented from exceeding the critical temperature. According to the experimental results, at the critical temperature $\left(65^{\circ} \mathrm{C}\right.$ is here taken for safety reasons), the $\mathrm{CO}$ concentration in the 12 \# coal seam of Bulianta Coal Mine is about $90-130$ ppm. At the same time, based on the amount of various gases produced after coal water immersion and drying (i.e., after the temperature exceeds $100^{\circ} \mathrm{C}$ ), it is concluded that the moisture content of $16.05 \%$ is most favours coal spontaneous combustion.

\section{Data Availability}

The data utilized to support the findings of this study are available from the corresponding author upon request.

\section{Conflicts of Interest}

The authors declare that they have no conflicts of interest.

\section{Acknowledgments}

The authors gratefully acknowledge the financial support from the China Energy Investment Group Technology Innovation Program (201391548036) and on-site technical guidance and treatment of the problem from technical staff in the Coal and Transportation Industry Management Department, China Energy Investment Group. 


\section{References}

[1] F. Li, S. G. An, and Z. Q. Xing, "Experimental study on pore structure and spontaneous combustion characteristics of submerged coal," Journal of Coal Science and Technology, vol. 47, no. S2, pp. 208-212, 2019.

[2] C. F. Xu, Research on Macro Characteristics and Control Technology of Spontaneous Combustion of Waterish Logged Coal, China University of Mining \& Technology, Beijing, China, 2015.

[3] J. C. Xu, Determination Theory of Dangerous Area of Coal Spontaneous Combustion, China Coal Industry Press, Beijing, China, 2001.

[4] R. E. Jones and D. T. A. Townend, "Oxidation of coal," Journal of Society Chemical Industry, vol. 68, no. 2, pp. 193-197, 1949.

[5] C. Krger and E. Beier, "Die Verwrtterung von Steinkoh2len," Brennstoff-Chemie, vol. 43, no. 4, pp. 328-329, 1962.

[6] X. Z. Zheng, Y. H. Lu, Y. Xiao, Y. H. Zhao, and Q. W. Li, "Experimental research on the influence of high moisture content on coal spontaneous combustion parameters," Journal of Safety and Environment, vol. 14, no. 4, pp. 71-75, 2014.

[7] S. C. Banerjee, Spontaneous Combustion of Coal and Mine Fires, A. A. Balkema Publishers, Rotterdam, Netherlands, 1985.

[8] T. X. Ren, J. S. Edwards, and D. Clarke, "Adiabatic oxidation study on the propensity of pulverised coals to spontaneous combustion," Fuel, vol. 78, no. 14, pp. 1611-1620, 1999.

[9] L. He and D. M. Wang, "Influence of moisture on absorbed oxygen and released heat of coal," Journal of China University of Mining \& Technology, vol. 34, no. 3, 2005.

[10] Deng, Y. Zhang, C. H. Li, Q. W. Li, L. J. Wu, and Y. J. He, "Research of limit parameters and oxidation kinetics of waterlogging coal self-ignition," Journal of Coal Technology, vol. 35, no. 3, 2016.

[11] K. Wang, Study on the Oxidation Reaction and Kinetics at Low Tempeature of Jurassic Coal in North Shaanxi, Xi'an University of Science and Technology, Xian, China, 2015.

[12] J. Song, N. Liu, W. J. Chen, and C. Xiao, "Experiments on the formation of $\mathrm{CO}_{2}$ hydrate with porous media," Journal of low temperature and specialty gases, vol. 30, no. 3, 2012.

[13] Y. N. Zhang, Study on the Microsmic Characteristics and Macro Parameters in the Process of Coal Oxidation and Spontaneous Combustion, Xi'an University of Science and Technology, Xian, China, 2012.

[14] Y. B. Tang, Low-temperature Oxidation of Coal-SurfaceGroups Based on Model Compounds, China University of Mining and Technology, Xian, China, 2014.

[15] Q. W. Li, Fundamental Study on the Thermokinetics Process of Coal Oxidation under Oxygen-Depleted Atmosphere, Xi'an University of Science and Technology, Xian, China, 2018.

[16] H. H. Xin, Exploring of Stage Evolution Characteristics and Reaction Mechanism of Oxygen-Lean Combustion in Coal Fire, China University of Mining and Technology, Xian, China, 2016.

[17] X. H. Chang, D. M. Wang, and H. L. Jia, "Thermogravimetric determination of the critical oxygen volume fraction for spontaneous combustion of coal," Journal of China University of Mining \& Technology, vol. 41, no. 4, pp. 526-550, 2012.

[18] Q. R. Shao, Z. J. Meng, G. F. Chen, X. Y. Fang, and W. J. Huo, "Advances of application of thermogravimetry coupled with infrared spectrometry technology," Journal of chemical analysis and meterage, vol. 29, no. 1, pp. 121-127, 2020.
[19] J. Y. Zhao, Study on the Kinetics and Micro-structures Characteristics of Huainan Coal in the Oxidation Process, Xi'an University of Science and Technology, Xian, China, 2017.

[20] L. Li, Self-activation Theory and Process of Spontaneous Combustion of Coal, Chongqing University, Chongqing, China, 2008.

[21] R. Z. Hu, Thermal Analysis Kinetics, Science press, Beijing, China, 2001.

[22] E. Urbanovici, C. Popescu, and E. Segal, "Improved iterative version of the coats-redfern method to evaluate non-isothermal kinetic parameters," Journal of Thermal Analysis and Calorimetry, vol. 58, no. 3, pp. 683-700, 1999.

[23] A. Mianowski and R. Bigda, "The kissinger law and isokinetic effect," Journal of Thermal Analysis and Calorimetry, vol. 75, no. 1, pp. 355-372, 2004.

[24] D. Lopez, Y. Sanada, and F. Mondragon, "Effect of lowtemperature oxidation of coal on hydrogen-transfer capability," Fuel, vol. 77, no. 14, pp. 1623-1628, 1998.

[25] Y. N. Zhang, S. R. Li, Z. M. Luo, F. M. Cheng, and Y. C. Wang, "Study on coal spontaneous combustion features of temperature rising system based on oil bathing program," Journal of Coal Science and Technology, vol. 38, no. 8, pp. 85-88, 2010. 